\title{
Air trapping is associated with heterozygosity for Alpha-1 Antitrypsin mutations in patients with asthma
}

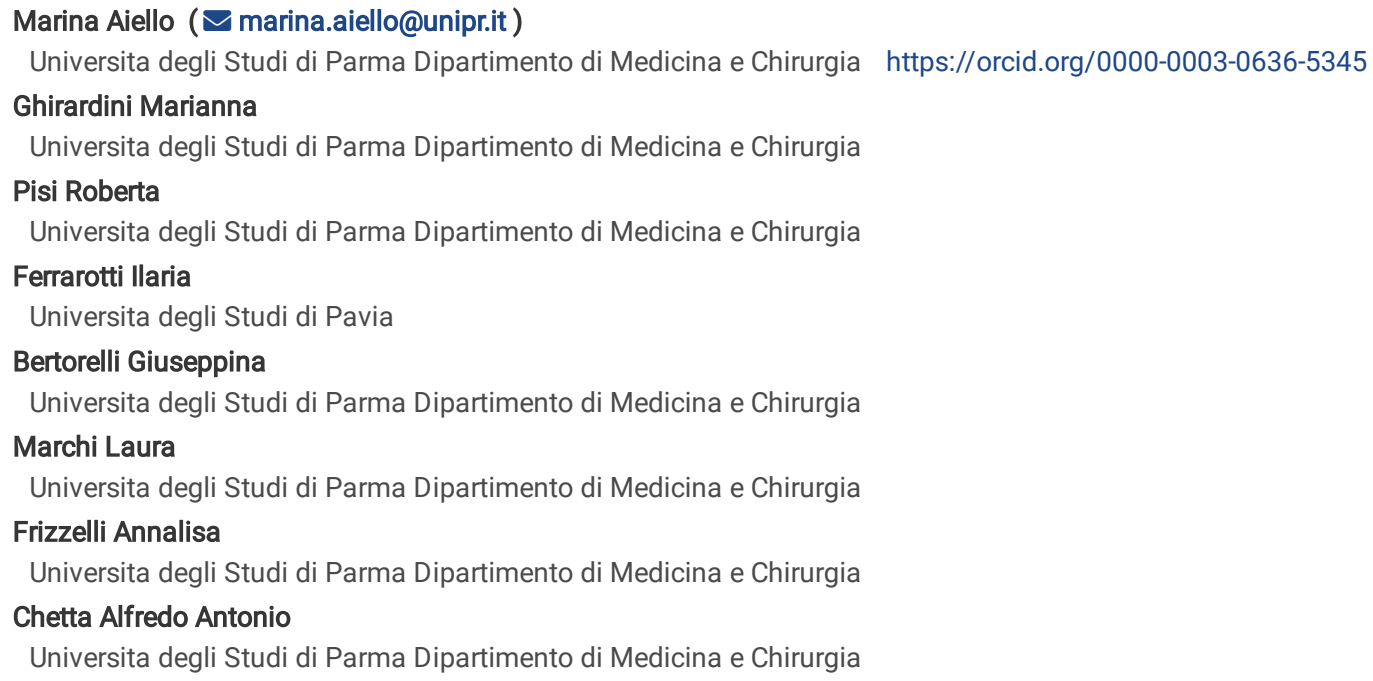

Keywords: Alpha-1 Antitrypsin Deficiency, Asthma, Lung function tests, Proteinase Inhibitor, Genotype

Posted Date: April 30th, 2020

DOI: https://doi.org/10.21203/rs.3.rs-23377/v1

License: @ (i) This work is licensed under a Creative Commons Attribution 4.0 International License. Read Full License

Version of Record: A version of this preprint was published at Respiration on January 1st, 2021. See the published version at https://doi.org/10.1159/000513072. 


\section{Abstract}

Background: Alpha-1 Antitrypsin Deficiency (AATD) is a hereditary genetic disorder involving lungs in adults, characterized by low serum concentration of the protein alpha-1 antitrypsin (AAT). Several reports indicate that asthma is common in AATD patients, but there are only few data on respiratory function in asthmatic patients with AATD. The aim of the study is to evaluate lung function in asthmatic outpatients with AATD vs. asthmatic subjects without AATD.

Methods: We performed the quantitative analysis of the serum concentration of AAT in 600 outpatients affected by mild to moderate asthma from the University Hospital of Parma, Italy. Fifty-seven of them underwent the genetic analysis subsequently, they were subdivided into AATD and non-AATD subjects. All the AATD patients had a heterozygous genotype, except one (PI*SS). We assessed the lung function through a flow-sensing spirometer and the small airways parameters through an impulse oscillometry system.

Results: The values of FVC (\% predicted) and of the RV/TLC (\%) ratio were respectively lower and higher in patients with AATD vs. patients without AATD, showing a significantly greater air trapping ( $p=0.014$ and $p=0.017$ respectively). Moreover, patients with AATD in comparison to patients without AATD showed lower $\mathrm{FEV}_{3}$ (\% predicted) and $\mathrm{FEV}_{6}(\mathrm{~L})$ spirometric values, reflecting a smaller airways contribution.

Conclusions: AATD in asthmatic heterozygote patients with $\mathrm{P}{ }^{\star} \mathrm{MZ}$ and $\mathrm{PI}$ MS genotypes was associated with small airways dysfunction and with lung air trapping.

\section{Background}

Alpha-1 Antitrypsin Deficiency (AATD) is a genetic condition that predisposes subjects to pulmonary diseases. It is characterized by a reduced serum concentration of the Alpha-1 Antitrypsin (AAT) protein. The relationship between AATD and respiratory diseases has been a topic of research activity since this deficiency was discovered in the early $1960 \mathrm{~s}^{1}$. Previous studies suggested an association between AATD and asthma ${ }^{2,3,4}$; on this basis, the literature data recommend that all adult-onset asthmatic patients should be screened for AATD ${ }^{5,6}$.

Pulmonary function has been studied especially in patients affected by Chronic Obstructive Pulmonary Disease (COPD) and severe AATD ${ }^{7,8}$; a few data are available on respiratory function in asthmatic patients with AATD.

We hypothesized that asthmatic patients affected by AATD could have abnormal spirometric and oscillometric values compared to asthmatic patients without AATD. Therefore, the first objective of this study was to evaluate lung function in asthmatic outpatients affected by AATD vs. asthmatic subjects without AATD. Subsequently, we focused on the heterozygote patients with $\mathrm{PI}{ }^{\star} \mathrm{MZ}$ and $\mathrm{PI}{ }^{\star} \mathrm{MS}$ following our study population genotypes.

\section{Methods}

\section{Study subjects and data collection}

This study has been performed at the University of Parma (Italy) over a period of 12 months during the scheduled office visits. We enrolled 57 mild to moderate asthmatic outpatients, 18 years of age or older, of both genders.

Asthma diagnosis was based on the combined presence of respiratory symptoms, reversible airflow obstruction and bronchial hyperactivity, as assessed by the methacholine (MCh) test ${ }^{9,10}$.

Patients with other concomitant lung diseases were excluded from the study. We recorded the following data in all asthmatic patients: anthropometric variables (sex, age, body mass index - BMI in $\mathrm{kg} / \mathrm{m}^{2}$ ), smoking habits (former/non-smoker), number of packs per year, AAT serum concentration and score of Asthma Control Test (ACT) ${ }^{11}$ to assess symptoms and asthma-related morbidity. None of the patients was an active smoker at the time of enrollment in the study.

The study was approved by the Hospital Ethics Committee of North Emilia Area (approval number: 33503, dated September 04 ${ }^{\text {th }}$, 2018) in agreement with the Declaration of Helsinki. Written informed consent was obtained from all participants before inclusion.

\section{Study design}

Following our clinical procedure, 600 asthmatic outpatients underwent a concomitant quantitative analysis of the serum concentrations of AAT (mg/dL) and C-reactive Protein (CRP). The CRP (mg/L) was used as internal control of analysis ${ }^{12}$. Consistently with the literature data ${ }^{13,14}, 52$ out of 600 asthmatic patients were submitted to sequencing of the SERPINA1 gene due to a serum AAT concentration $\leq 113 \mathrm{mg} / \mathrm{dL}$. We performed the genetic analysis also in 9 asthmatic patients with a serum AAT concentration $>113 \mathrm{mg} / \mathrm{dL}$ but with the presence of a clinical and/or family history that could be related to AAT deficiency ${ }^{12}$. We excluded 6 patients with respiratory comorbidities from the study.

Furthermore, the relatives of asthmatic patients with AATD underwent genetic analysis ${ }^{13}$. Only 2 of them were included in our study as asthmatic. They were heterozygous, with $\mathrm{PI}{ }^{\star} \mathrm{MS}$ and $\mathrm{PI} \mathrm{MZ}$ genotypes, and their serum AAT concentration was $>113 \mathrm{mg} / \mathrm{dL}$.

On the basis of the genetic test results, the study population was divided in two groups: 35 patients with a non-pathological genotype (PI*MM) and 22 patients with a pathological genotype. The subsequent comparisons were performed between the heterozygote genotypes $\mathrm{P}{ }^{\star} \mathrm{MS}$ and $\mathrm{P}{ }^{\star} \mathrm{MZ}$, following the prevalence of intermediate AATD of the study population. 
The participant selection process is shown in the Consort diagram (Fig. 1).

\section{Spirometry}

We used a flow-sensing spirometer connected to a computer for data analysis (Vmax22 and 6200; Sensor-Medics; Yorba Linda, CA, USA) to measure lung function parameters. Forced expiratory volume in the $1^{\text {st }}$ second $\left(\mathrm{FEV}_{1}\right)$ and forced vital capacity $(\mathrm{FVC})$ were recorded and expressed as absolute values (in liters, $L$ ) and as percentage of a predicted value (\% predicted). The $\mathrm{FEV}_{1} / \mathrm{FVC}$ value was recorded as a ratio. Total lung capacity (TLC) was obtained as the sum of functional residual capacity and the linked inspiratory capacity (IC). Residual volume (RV) value was obtained by subtracting vital capacity from TLC. The ratio of residual volume to total lung capacity (RV/TLC) was also recorded as index of lung air trapping. Diffusing capacity for carbon monoxide (DLCO) and transfer coefficient of the lung for carbon monoxide ( $\mathrm{KCO}$ ) were measured as a percentage of predicted value (\% predicted). At least 3 measurements were taken for each spirometry test and lung volume variable to ensure data reproducibility ${ }^{15}$.

In order to measure the smaller airway contributions, forced expiratory volume in 3 seconds $\left(\mathrm{FEV}_{3}\right.$, in $\mathrm{L}$ and \% predicted) and forced expiratory volume in 6 seconds $\left(\mathrm{FEV}_{6}\right.$, in $\left.\mathrm{L}\right)$ were recorded. The $\mathrm{FEV}_{3} / \mathrm{FVC}, \mathrm{FEV}_{6} / \mathrm{FVC}$ and $\mathrm{FEV}_{3} / \mathrm{FEV}_{6}$ values were recorded as ratio and were considered as measures able to detect small airway dysfunctions (SAD). Moreover, we recorded maximal expiratory flow-rates at 25, 50 and 75\% of the vital capacity $\left(\mathrm{MEF}_{25}, \mathrm{MEF}_{50}, \mathrm{MEF}_{75}\right.$, expressed as L/s and as \% predicted).

\section{Impulse Oscillometry}

Impulse Oscillometry (IOS) was performed using the Jaeger MasterScreen-IOS instrument (Carefusion Technologies, San Diego, CA, USA) as per standard recommendations ${ }^{16}$. Patients were asked to wear a nose clip and were seated during tidal breathing with their neck slightly extended and their lips sealed tightly around the mouthpiece, while firmly supporting their cheeks with their hands. The procedure was repeated at least 3 times, each lasting 30 s, and mean values were chosen. Respiratory resistances at 5 and $20 \mathrm{~Hz}$ (R5 and R20, in kPa/[L/s]) were used as index of total and proximal airway resistance, respectively, and the fall in resistance from 5 to $20 \mathrm{~Hz}$ (R5-R20 in kPa/[L/s]) was considered an index for the resistance of peripheral airways. The reactance at $5 \mathrm{~Hz}$ (X5 in $\mathrm{kPa} /[\mathrm{L} / \mathrm{s}])$ and the resonant frequency $\left(\mathrm{F}_{\text {res }}\right.$ in $\left.\mathrm{kPa} /[\mathrm{L} / \mathrm{s}]\right)$ were considered representative markers of peripheral airway dysfunction. Moreover, impedance at 5 $\mathrm{Hz}(\mathrm{Z} 5$ in $\mathrm{kPa} /[\mathrm{L} / \mathrm{s}])$ and the area of reactance $(\mathrm{AX}$ in $\mathrm{kPa} /[\mathrm{L} / \mathrm{s}])$ were measured.

\section{Statistical Analysis}

A Kolmogorov-Smirnov test was used to assess the normality of distribution in all variables.

Group data with normal distribution are presented as mean $\pm S D$, while data with non-normal distribution are presented as median values $\left(1^{\text {st }}\right.$ quartile; $3^{\text {rd }}$ quartile). Comparisons of means among groups were performed through the analysis of variance (t-tests) for continuous variables. The non parametric Kruskal-Wallis test was used for data with non-Gaussian distribution. Chi-square tests and Fisher exact tests were performed for qualitative variables.

For correlation analysis, the Pearson or Spearman correlation coefficients were used for linear or normally distributed variables and for non linear or non normally distributed variables, respectively. Receiver operating characteristic (ROC) curves were generated to calculate the area under the curve (AUC) with $95 \%$ confidence interval $(\mathrm{Cl})$ and to select the best cut-off value with the related sensibility and specificity.

A $p$ value $<0.05$ was considered statistically significant. Statistical analysis was performed using the SPSS Statistics version 25.0 software package (IBM, Armonk, New York, USA).

\section{Results}

In all asthmatic patients, the mean age was $57 \pm 15$ years and $54 \%$ were female subjects; the median serum AAT concentration was 108.0 [97.9; 111.5$]$ mg/dL. Asthmatic subjects were classified as patients with AATD $(n=22 ; 38.6 \%)$ and without AATD $(n=35 ; 61.4 \%)$ according to their PI* (Proteinase Inhibitor) genotype. The frequency of deficient genotypes was: 11 (19.3\%) patients with the PI*MS genotype, 9 (15.8\%) with the PI*MZ genotype, one (1.75\%) patient with the PI* $\mathrm{MM}_{\text {Malton }}$ and one (1.75\%) patient with the PI*SS genotype (Fig. 2). The median values of AAT concentration were lower in patients affected by AATD vs. PI*MM patients ( $97.8 \mathrm{mg} / \mathrm{dL}$ vs. $111 \mathrm{mg} / \mathrm{dL}, p=0.000)$, while values of BMI were higher in patients affected by AATD $v s$. PI*MM patients (27.5 $\mathrm{kg} / \mathrm{m}^{2}$ vs. $\left.25 \mathrm{~kg} / \mathrm{m}^{2}, p=0.007\right)$. Demographic and clinical characteristics of the patients are summarized in Table 1. No significant differences were observed in pack/years data and mean age at smoking onset between groups with and without genetic AATD. Forty-three asthmatic patients (75\% of cases) showed atopy, with skin-test positive for common aeroallergens, 20 were with AATD ( $91 \%$ of cases) and 23 without AATD (66\% of cases) ( $p=0.031)$.

The results of the respiratory function tests are summarized in Table 2. FVC (\%) and the RV/TLC ratio (\%) were respectively lower and higher in patients with AATD than in those without AATD, showing a significantly greater air trapping ( $p=0.014$ and $p=0.017$, respectively), as shown Fig 3 . We did not find any significant difference in other variables.

Table 3 summarizes the small airways values measured through oscillometry and spirometry in asthmatic patients. Patients with AATD showed lower values of $\mathrm{FEV}_{3}$ (\% predicted) and $\mathrm{FEV}_{6}(\mathrm{~L})$ in comparison to those without AATD (Fig. 3 and 4 ).

Significant results obtained by grouping the patients according to their $\mathrm{Pl}^{\star}$ genotype are summarized in Table 4. No difference in lung function test results and in general characteristics was observed between groups with $\mathrm{PI} * \mathrm{MS}$ and $\mathrm{PI}{ }^{\star} \mathrm{MZ}$ genotypes, with the exception of the median values of AAT concentration (100 vs. $90.7 \mathrm{mg} / \mathrm{dL}, p=0.016$ ). However, we found an increased value of the RV/TLC ratio (\%) in the subgroup of asthmatic patients with the PI*MS genotype 
compared to the $\mathrm{P} I^{\star} \mathrm{MM}$ genotype $(\mathrm{p}=0.043)$. The mean values of $\mathrm{FEV}_{6}(\mathrm{~L})$ were $2.73 \mathrm{~L}$ and $3.55 \mathrm{~L}$ in the $\mathrm{P} \mathrm{I}^{\star} \mathrm{MS}$ and $\mathrm{P} \mathrm{I}^{\star} \mathrm{MM}$ genotypes respectively, but the difference did not reach a statistical significance $(p=0.060)$.

We found statistically significant differences when we compared lung function test results and general characteristics in asthmatic patients with the $\mathrm{PI} \times \mathrm{MZ}$ genotype $v s$. those with the PI*MM genotype. The median AAT concentration $(90.7 \mathrm{mg} / \mathrm{dL} v s .111 \mathrm{mg} / \mathrm{dL}, p=0.000)$ and FVC value (97.2\% vs. $109 \%$ predicted, $p=0.040$ ) were lower, while the mean value of $\mathrm{FEV}_{3}$ was $82.9 \pm 11 \%$ vs. $95.9 \pm 12 \%$ predicted $(p=0.007)$ respectively, in both groups. The RV/TLC (\%) ratio mean values were $42.9 \%$ and $36.3 \%$ in the $\mathrm{PI} \mathrm{MZ}$ and $\mathrm{PI} * \mathrm{MM}$ genotypes respectively, without reaching a statistical significance $(p=0.079)$.

The comparison between asthmatic patients with a PI*MM genotype and grouped patients with $\mathrm{PI} M \mathrm{MS}$ and $\mathrm{PI}$ MZ genotypes revealed significant differences with reference to the FVC, RV/TLC, TLC, FEV 3 , FEV 6 and R20 values.

No difference in pulmonary function was found by splitting the AATD patients into smoker and non-smoker subgroups (data not shown).

We found a significant and positive correlation $(p=0.041 ; \mathrm{r}=0.894)$ between the RV/TLC ratio and the years of smoking in the group of asthmatic patients with AATD; we did not find the same correlation in the group of patients without AATD ( $p=0.349)$ (data not shown).

No significant correlation was found among AAT values, lung function test results and impulse oscillometry values in asthmatic patients with AATD.

The ROC curve was calculated to set the value of the RV/TLC ratio able to be likely associated to the presence of an AATD in asthmatic patients (Fig. 5), and revealed an AUC of 0.681 (standard error [SE] $0.070 ; 95 \% \mathrm{Cl} 0.543-0.819 ; p<0.05$ ) with a RV/TLC \% ratio cut-off value of 29.2 (sensitivity 0.864 , specificity 0.429).

\section{Discussion}

The present study assessed the lung function in two groups of mild to moderate asthmatic patients with and without AATD and showed significantly lower FVC (\%) values in AATD patients vs. subjects without AATD. Furthermore, we showed that the values of the RV/TLC ratio in AATD patients were significantly higher vs. subjects without AATD. Although the results we obtained in the spirometry-derived parameters FVC and RV/TLC ratio should be interpreted with caution, they suggest the presence of air trapping, which marker of the airway obstruction in asthmatic patients with AATD. Hall et al. ${ }^{17}$ found no significant difference in spirometry and static lung volumes in a population of asymptomatic non-smoking adults with intermediate AAT. Differences in study populations might explain the different results we obtained $v s$. the study by Hall et al. ${ }^{17}$.

Furthermore, in our study there was no statistically significant difference both in AATD patients and in the PI*MM subjects when their smoking habits were considered (Table 1). In the group of asthmatic patients with AATD, the RV/TLC ratio correlates significantly with the years of smoking; this correlation was not significant in the 35 asthmatic patients without AATD. These results highlight an increased risk for impaired lung function related to cigarette smoke exposure in asthmatic patients with AATD compared to asthmatic subjects without AATD.

A study limitation is represented by the low number of subjects and consequently by the low percentage of former smokers in the group of AATD patients (5 and $23 \%$, respectively). However this percentage reflects the rate of former smokers in the general asthmatic population, ranging from $22 \%$ to $43 \%$, as reported in literature ${ }^{18}$.

The RV/TLC ratio has received little emphasis in studies focusing on pulmonary dysfunction in AATD subjects, while other lung function-related parameters $\left(\mathrm{FEV}_{1}, \mathrm{FEV}_{1} / \mathrm{FVC}\right.$ ratio and $\left.\mathrm{KCO}\right)$ have been taken into consideration ${ }^{19,7}$.

While $\mathrm{FEV}_{1}$ values can indicate large airway obstructions, $\mathrm{FEV}_{3}$ and $\mathrm{FEV}_{6}$ values, representing the latter fraction of forced exhalation, could better reflect smaller airway obstructions, and be a more sensitive measure to diagnose early airway obstruction ${ }^{20}$. Furthermore, $\mathrm{FEV}_{3}$ and $\mathrm{FEV}_{6}$ are accurate and reliable alternatives to FVC in the assessment of airflow limitation in asthmatic patients ${ }^{21}$.

Our data suggest that the increased inflammation in asthmatic patients with AATD causes a more evident and early dysfunction and narrowing in the small airways, where $\mathrm{FEV}_{3}$ and $\mathrm{FEV}_{6}$ values were significantly lower compared to asthmatic patients without AATD. On the other hand, no significant difference in R5-R20 values has been found. This may suggest that damage to elastic tissue in patients with AATD could be better revealed through spirometric evaluations of small airways performed with forced maneuvers compared to resting evaluations such as oscillometric measurements, because of the collapsibility of small airways.

Following the prevalence of heterozygous forms in the study population, we focused on patients with PI*MS and the PI*MZ genotypes. The prevalence in our data of deficient $S$ and $Z$ alleles and the prevalence of heterozygous forms are expected results according to the trend observed in literature data ${ }^{12,22}$. In more detail, the presence of $S$ allele has been associated both with a high risk of non-specific bronchial hyperresponsiveness, and with a higher asthmatic disease $v s$. the general population ${ }^{23,24}$. Other studies showed a greater asthma severity in children and adolescents when associated to $Z$ allele in the heterozygous form ${ }^{25}$. Eden et al. found a three-fold higher prevalence of asthma in the $\mathrm{PI}{ }^{\star} \mathrm{MZ}$ group $v$ s. the $\mathrm{PI}{ }^{\star} \mathrm{ZZ}$ group ${ }^{26}$.

We found SAD and lung air trapping when $\mathrm{PI} M \mathrm{MS}$ and $\mathrm{PI} \mathrm{MZ}$ genotypes were compared to the $\mathrm{PI}$ MM genotype. In addition, we did not find any significant difference in lung function test results between the PI*MS and the PI*MZ genotypes; the only difference concerned the AAT protein concentration.

We did not find any significant difference in $\mathrm{FEV}_{1}, \mathrm{FEV}_{1} / \mathrm{FVC}, \mathrm{TLC}$ and $\mathrm{KCO}$ values between $\mathrm{PI} \mathrm{MS}$ asthmatic patients and $\mathrm{PI}{ }^{\star} \mathrm{MM}$ patients. This finding is consistent with Miravitlles et al. ${ }^{27}$ results. In addition, our data showed a significant difference between the two groups of patients in the RV/TLC ratio values,

Page $4 / 13$ 
a lung function parameter not evaluated by Miravitlles et al.

\section{Conclusions}

In conclusion, our data showed the presence of a significant pulmonary air trapping and of a SAD in asthmatic heterozygote patients with $\mathrm{PI} M \mathrm{MZ}$ and $\mathrm{PI} \mathrm{MS}$ compared to PI*MM asthmatic patients.

Further studies will be required to confirm if lung air trapping and SAD could possibly be associated with a more rapid decline, in order to identify the patients most likely to benefit from an effective intervention.

\section{Abbreviations}

AATD: Alpha-1 antitrypsin deficiency; AAT: Alpha-1 antitrypsin; ACT: Asthma control test; AUC: Area under the curve; AX: Area of reactance; BMI: Body mass index; COPD: Obstructive pulmonary disease; CRP: C-reactive protein; DLCO: Diffusing capacity for carbon monoxide; FEV $\mathrm{F}_{1}$ : Forced expiratory volume in one second; $\mathrm{FEV}_{3}$ : Forced expiratory volume in three second; $\mathrm{FEV}_{6}$ : Forced expiratory volume in six second; FEV 1 / FVC: Forced expiratory volume in one second to forced vital capacity ratio; $F_{\text {Res: }}$ Resonant Frequency; FVC: Forced vital capacity; IC: Inspiratory capacity; IOS: Impulse Oscillometry; KCO: Transfer coefficient of the lung for carbon monoxide; $\mathrm{MEF}_{25}, \mathrm{MEF}_{50}, \mathrm{MEF}_{75}$, maximal expiratory flow-rates at 25, 50 and 75\% of the inspiratory vital capacity; $\mathrm{MCh}$ : Methacholine; PI: Proteinase inhibitor; ROC: Receiver operating characteristics; RV: Residual volume; RV /TLC: Residual volume to total lung capacity ratio; R5, resistance at 5 $\mathrm{Hz}$; R20, resistance at $20 \mathrm{~Hz}$; SAD: small airways dysfunction TLC: Total lung capacity; X5: Reactance at $5 \mathrm{~Hz}$; Z5: Impedance at $5 \mathrm{~Hz}$.

\section{Declarations}

\section{Ethics approval and consent to participate}

This study was approved by the Hospital Ethics Committee of North Emilia Area (approval number: 33503 , dated September $04^{\text {th }}, 2018$ ) in agreement with the Declaration of Helsinki. This research was carried out in accordance with the approved guidelines. Written informed consent was obtained from all participants before inclusion.

\section{Consent for publication}

Not applicable.

\section{Availability of data and materials}

The datasets used and/or analyzed during the current study are available from the corresponding author on reasonable request.

\section{Competing interests}

The authors declare that they have no competing interests

\section{Funding}

There was no funding source for this study.

\section{Authors' contributions}

CA and AM conceived and designed the study, had full access to all of the data, and took responsibility for the integrity of the data and the accuracy of the data analysis. AM, GM, FI, BG analyzed and contributed to the statistic of the data. GM and PR contributed to the collection clinical data. AM prepared and reviewed the manuscript, in consultation with FA, GM and ML. All other authors provided critical feedback and approved the final draft.

\section{Acknowledgments}

The authors acknowledge and appreciate the assistance for statistical analysis of Dr. M. Rossi from the Department of Medicine and Surgery, University Hospital of Parma (Italy).

\section{References}

(1) Laurell CB, Eriksson S. The electrophoretic alpha ${ }_{1}$-globulin pattern in serum alpha ${ }_{1}$-antitrypsin deficiency. Scand J Clin Lab Invest. 1963; 15 : 132-140.

(2) McElvaney NG, Stoller JK, Buist AS, et al. Baseline characteristics of enrollees in the National Heart, Lung and Blood Institute Registry of alpha 1-antitrypsin deficiency. Alpha 1-Antitrypsin Deficiency Registry Study Group. Chest. 1997; 111: 394-403.

(3) Eden E, Mitchell D, MehIman B, et al. Atopy, asthma, and emphysema in patients with severe alpha-1-antitrypysin deficiency. Am J Respir Crit Care Med. 1997; 156: 68-74

(4) Siri D, Farah H, Hogarth DK. Distinguishing alpha1-antitrypsin deficiency from asthma. Ann Allergy Asthma Immunol. 2013; 111: 458-64. 
(5) No authors listed. Alpha 1-antitrypsin deficiency: memorandum from a WHO meeting. Bull World Health Organ 1997; 75: $397-415$.

(6) Miravitlles M, Dirksen A, Ferrarotti I, et al. European Respiratory Society statement: diagnosis and treatment of pulmonary disease in $\mathrm{a}_{1}$-antitrypsin deficiency. European Respiratory Journal 2017; 50: 1700610.

(7) Dawkins PA, Dawkins CL, Wood AM, et al. Rate of progression of lung function impairment in a1-antitrypsin deficiency. Eur Respir J. 2009; 33:1338-1344.

(8) Hiller AM, Piitulainen E, Jehpsson L, et al. Decline in $\mathrm{FEV}_{1}$ and hospitalized exacerbations in individuals with severe alpha-1 antitrypsin deficiency. Int J Chron Obstruct Pulmon Dis. 2019; 14: 1075-1083.

(9) Coates AL, Wanger J, Cockcroft DW, Culver BH; Bronchoprovocation Testing Task Force: Kai-Håkon Carlsen, Diamant Z, Gauvreau G, Hall GL, Hallstrand TS, Horvath I, de Jongh FHC, Joos G, Kaminsky DA, Laube BL, Leuppi JD, Sterk PJ. ERS technical standard on bronchial challenge testing: general considerations and performance of methacholine challenge tests. Eur Respir J. 2017 May 1;49(5)

(10) Global Initiative for Asthma (GINA). Global Strategy for Asthma Management and Prevention, 2018. Available online at ginasthma.org.

(11) Jia CE, Zhang HP, Lv Y, et al. The Asthma Control Test and Asthma Control Questionnaire for assessing asthma control: Systematic review and metaanalysis. J Allergy Clin Immunol. 2013; 131: 695-703.

(12) Ferrarotti I, Thun GA, et al. Serum levels and genotype distribution of a1-antitrypsin in the general population. Thorax. 2012;67:669-674.

(13) Miravitlles M, Dirksen A, Ferrarotti I, et al. European Respiratory Society statement: diagnosis and treatment of pulmonary disease in a1-antitrypsin deficiency. Eur Respir J. 2017; 50.

(14) Gorrini M, Ferrarotti I, et al. Validation of a Rapid, Simple Method to Measure 1-Antitrypsin in Human Dried Blood Spots. Clin Chem. 2006 ; 52 : 899-901.

(15) Pellegrino R, Viegi G, Brusasco V, et al. Interpretativestrategies for lung function tests. Eur Respir J. 2005; 26: 948-968.

(16) Oostveen E, MacLeod D, Lorino H, et al.ERS Task Force on Respiratory Impedance Measurements: The forced oscillation technique in clinical practice: methodology, recommendations and future developments. Eur Respir J. 2003; 22: 1026-1041.

(17) Hall WJ, Hyde RW et al. Pulmonary Abnormalities in Intermediate Alpha-1-Antitrypsin Deficiency. J Clin Invest 1976;58(5):1069-1077

(18) Thomson NC, Chaudhuri R, Livingsto E. Active cigarette smoking and asthma. Clin Exp Allergy. 2003; 33: 1471-1475.

(19) Vance JC, Hall WJ, Schwartz RH, et al. Heterozygous alpha-1-antitrypsin deficiency and respiratory function in children. 1977; 60: $263-272$.

(20) Hansen JE, Sun XG, Wasserman K. Discriminating measures and normal values for expiratory obstruction. Chest. 2006; $129: 369-377$.

(21) Lutfi MF. Acceptable alternatives for forced vital capacity in the spirometric diagnosis of bronchial asthma. Int J Appl Basic Med Res. 2011 ; 1: 20-23.

(22) Suárez Lorenzo I, Rodríguez de Castro F, et al. Alpha 1 antitrypsin distribution in an allergic asthmatic population sensitized to house dust mites. Clin Transl Allergy 8:44, 2018.

(23) Townley RG, Southard JG, Radford P, et al. Association of MS Pi phenotype with airway hyperresponsiveness. Chest 1990; 98: 594-599.

(24) Rosenfeld GB. $a_{1}$-antitrypsin heterozygosity and spirometric function in chronic asthma. J Allergy Clin Immunol. 1976; 57: $218-219$.

(25) Katz RM, Lieberman J, Siegel SC. Alpha- ${ }_{1}$-antitrypsin levels and prevalence of Pi variant phenotypes in asthmatic children. J Allergy Clin Immunol. 1976; 57: 41-45.

(26) Eden E, Strange C, Holladay B, et al. Asthma and allergy in alpha-1 antitrypsin deficiency. Respir Med. 2006; 100: $1384-1391$.

(27) Miravitlles M, Vilà S, Torrella M, et al. Influence of deficient alpha1-anti-trypsin phenotypes on clinical characteristics and severity of asthma in adults. Respir Med. 2002; 96: 186-192.

\section{Tables}

Table 1. Demographic and laboratory data, smoking habits in reference to presence/absence of genetic AATD 


\begin{tabular}{|c|c|c|c|}
\hline Variables & Asthmatic patients & AATD & Non AATD \\
\hline & 57 & 22 & 35 \\
\hline \multicolumn{4}{|l|}{ Subjects, nr } \\
\hline $\mathrm{BMI}, \mathrm{kg} / \mathrm{m}^{2}$ & $26.0[24.0 ; 29.0]$ & $27.5[25.0 ; 30.0]^{p}$ & $25.0[23.0 ; 28.0]$ \\
\hline Age, years & $57 \pm 15$ & $57 \pm 16$ & $56 \pm 15$ \\
\hline Women, \% & 54 & 64 & 46 \\
\hline Non-smokers, nr (\%) & $44(77)$ & 17(77) & $27(77)$ \\
\hline Former smokers, nr (\%) & $13(23)$ & $5(23)$ & $8(23)$ \\
\hline Pack/years, nr & $10[4 ; 20]$ & $10[8 ; 28]$ & $8[3 ; 19]$ \\
\hline Years of smoking, nr & $19 \pm 11$ & $21 \pm 10$ & $19 \pm 12$ \\
\hline AAT concentration, $\mathrm{mg} / \mathrm{dL}$ & $108.0[97.9 ; 111.5]$ & $97.8\left[83.2 ; 106.5^{p}\right.$ & $111.0[105.0 ; 115.0]$ \\
\hline Atopy, nr (\%) & $43(75)$ & $20(91)^{c}$ & $23(66)$ \\
\hline $\mathrm{ACT}$, total score & $25[23 ; 25]$ & $24[23 ; 25]$ & $25[23 ; 25]$ \\
\hline
\end{tabular}

Data are shown as number of patients (\%), means \pm SD or medians [1 st quartile; 3rd quartile].

Boldface variables are statistically significant.

Abbreviations: $n r$, number, $B M I$, body mass index; $A A T$, serum a ${ }_{1}$-antitrypsin; $A C T$, asthma control test.

${ }^{a} p$ value $=0.007$ vs. non $A A T D$.

${ }^{b} p$ value $=0.000 \mathrm{vs}$. non $A A T D$.

${ }^{c} p$ value $=0.031 \mathrm{vs}$. non AATD .

Table 2. Lung function tests in reference to presence/absence of genetic AATD 


\begin{tabular}{|c|c|c|c|}
\hline \multicolumn{2}{|l|}{ Variables } & AATD & Non AATD \\
\hline & 57 & 22 & 35 \\
\hline \multicolumn{4}{|l|}{ Subjects, nr } \\
\hline $\mathrm{FEV}_{1}, \mathrm{~L}$ & $2.53 \pm 0.90$ & $2.30 \pm 0.87$ & $2.67 \pm 0.90$ \\
\hline $\mathrm{FEV}_{1}, \%$ predicted & $92.7 \pm 15.2$ & $88.9 \pm 13.9$ & $95.0 \pm 15.6$ \\
\hline FVC, L & $3.55 \pm 1.13$ & $3.16 \pm 1.02$ & $3.80 \pm 1.14$ \\
\hline FVC, \% predicted & $108.2 \pm 16.2$ & $101.6 \pm 14.8^{a}$ & $112.3 \pm 15.9$ \\
\hline $\mathrm{FEV}_{1} / \mathrm{FVC}, \%$ & $71.0 \pm 9.9$ & $72.6 \pm 8.6$ & $70.0 \pm 10.6$ \\
\hline TLC, L & $5.86 \pm 1.18$ & $5.50 \pm 1.13$ & $6.08 \pm 1.16$ \\
\hline TLC, \% predicted & $106.7 \pm 12.6$ & $104.6 \pm 11.3$ & $107.9 \pm 13.4$ \\
\hline$R V, L$ & $2.25 \pm 0.61$ & $2.30 \pm 0.55$ & $2.22 \pm 0.65$ \\
\hline $\mathrm{RV}, \%$ predicted & $115.5 \pm 26.9$ & $121.4 \pm 26.7$ & $111.9 \pm 26.7$ \\
\hline $\mathrm{RV} / \mathrm{TLC}, \%$ & $38.8 \pm 10.1$ & $42.8 \pm 9.9^{b}$ & $36.3 \pm 9.5$ \\
\hline DLCO, \% predicted & $92.2 \pm 13.4$ & $90.3 \pm 13.4$ & $93.4 \pm 13.4$ \\
\hline KCO, \% predicted & $97.0[87.0 ; 109.4]$ & $96.0[86.8 ; 109.0]$ & $97.0[87.0 ; 111.0]$ \\
\hline
\end{tabular}

Data are shown as means \pm SD or medians [1st quartile; 3rd quartile].

Boldface variables are statistically significant.

Abbrevations: nr, number, $F E V_{1}$, forced expiratory volume in one second; FVC, forced vital capacity; FEV 1 / FVC, forced expiratory volume in one second to forced vital capacity ratio; TLC, total lung capacity; RV, residual volume; RV /TLC, residual volume to total lung capacity ratio; DLCO, diffusing capacity for carbon monoxide; $K C O$, transfer coefficient of the lung for carbon monoxide.

${ }^{a} p$ value $=0.014 \mathrm{vs}$. non AATD.

${ }^{b} p$ value $=0.017 \mathrm{vs}$. non $A A T D$.

Table 3. Values of small airways measured by impulse oscillometry and spirometry in reference to presence/absence of genetic AATD 


\begin{tabular}{|c|c|c|c|}
\hline \multicolumn{4}{|l|}{ Variables } \\
\hline & 57 & 22 & 35 \\
\hline \multicolumn{4}{|l|}{ Subjects, nr } \\
\hline $\mathrm{Z} 5, \mathrm{kPa} /(\mathrm{L} / \mathrm{s})$ & $0.47 \pm 0.16$ & $0.51 \pm 0.15$ & $0.43 \pm 0.17$ \\
\hline R5-R20, kPa/(L/s) & $0.07 \pm 0.08$ & $0.08 \pm 0.09$ & $0.07 \pm 0.07$ \\
\hline $\mathrm{R} 5, \mathrm{kPa} /(\mathrm{L} / \mathrm{s})$ & $0.43 \pm 0.14$ & $0.47 \pm 0.12$ & $0.40 \pm 0.15$ \\
\hline $\mathrm{R} 20, \mathrm{kPa} /(\mathrm{L} / \mathrm{s})$ & $0.36 \pm 0.10$ & $0.39 \pm 0.07$ & $0.34 \pm 0.12$ \\
\hline $\mathrm{AX}, \mathrm{kPa} /(\mathrm{L} / \mathrm{s})$ & $0.58[0.27 ; 1.37]$ & $0.64[0.35 ; 1.56]$ & $0.53[0.16 ; 1.14]$ \\
\hline $\mathrm{X} 5, \mathrm{kPa} /(\mathrm{L} / \mathrm{s})$ & $-0.15[-0.22 ;-0.11]$ & $-0.15[-0.28 ;-0.13]$ & $-0.14[-0.20 ;-0.08]$ \\
\hline $\mathrm{F}_{\mathrm{Res}}, \mathrm{Hz}$ & $16.00 \pm 5.65$ & $17.16 \pm 5.43$ & $15.03 \pm 5.75$ \\
\hline $\mathrm{FEV}_{3}, \mathrm{~L}$ & $3.12 \pm 1.12$ & $2.73 \pm 1.05$ & $3.38 \pm 1.10$ \\
\hline $\mathrm{FEV}_{3}, \%$ predicted & $91.8 \pm 14.9$ & $85.6 \pm 16.9^{a}$ & $95.9 \pm 12.1$ \\
\hline $\mathrm{FEV}_{6}, \mathrm{~L}$ & $3.24 \pm 1.13$ & $2.75 \pm 0.91^{b}$ & $3.55 \pm 1.16$ \\
\hline $\mathrm{FEV}_{3} / \mathrm{FVC}, \%$ & $89.5 \pm 4.8$ & $88.5 \pm 5.7$ & $90.2 \pm 4.1$ \\
\hline $\mathrm{FEV}_{6} / \mathrm{FVC}, \%$ & $95.4 \pm 3.7$ & $94.5 \pm 4.3$ & $96.0 \pm 3.1$ \\
\hline $\mathrm{FEV}_{3} / \mathrm{FEV}_{6}, \%$ & $92.4[89.9 ; 93.5]$ & $91.1[88.6 ; 93.1]$ & 93.1[91.8;93.7] \\
\hline $\mathrm{MEF}_{25}, \mathrm{~L} / \mathrm{s}$ & $0.57[0.34 ; 0.94]$ & $0.50[0.20 ; 0.65]$ & $0.58[0.42 ; 0.99]$ \\
\hline $\mathrm{MEF}_{25}, \%$ predicted & $37.4[31.2 ; 55.3]$ & $35.1[21.1 ; 43.5]$ & $40.5[32.7 ; 58.3]$ \\
\hline $\mathrm{MEF}_{50}, \mathrm{~L} / \mathrm{s}$ & $2.15[1.51 ; 3.22]$ & $2.09[0.70 ; 2.61]$ & $2.15[1.76 ; 3.38]$ \\
\hline $\mathrm{MEF}_{50}, \%$ predicted & $52.2[42.7 ; 68.6]$ & $50.6[22.0 ; 69.0]$ & $53.3[45.3 ; 71.5]$ \\
\hline $\mathrm{MEF}_{75}, \mathrm{~L} / \mathrm{s}$ & $4.87 \pm 2.20$ & $4.43 \pm 2.49$ & $5.15 \pm 1.97$ \\
\hline $\mathrm{MEF}_{75}, \%$ predicted & $78.1 \pm 27.7$ & $73.4 \pm 32.5$ & $81.2 \pm 24.2$ \\
\hline $\mathrm{MEF}_{75 / 25}, \mathrm{~L} / \mathrm{s}$ & $1.62[1.07 ; 2.59]$ & $1.50[0.53 ; 1.78]$ & $1.70[1.21 ; 2.73]$ \\
\hline $\mathrm{MEF}_{75 / 25}, \%$ predicted & $58.7 \pm 24.3$ & $54.3 \pm 29.2$ & $61.6 \pm 20.5$ \\
\hline
\end{tabular}

Data are shown as means \pm SD or medians [1st quartile; 3rd quartile].

Boldface variables are statistically significant.

Abbrevations: $n r$, number, Z5, impedance at $5 \mathrm{~Hz} ; R 5$, resistance at $5 \mathrm{~Hz} ; R 20$, resistance at $20 \mathrm{~Hz}$; $A X$, area of reactance; $X 5$, reactance at $5 \mathrm{~Hz}$; $F_{\text {Res }}$ Resonant Frequency; $F E V_{3}$, forced expiratory volume in three second; $F E V_{6}$, forced expiratory volume in six second; $M E F_{25}, M E F_{50}, M E F_{75}$, maximal expiratory flow-rates at 25,50 and $75 \%$ of the inspiratory vital capacity.

${ }^{a} p$ value $=0.018 v s$. non $A A T D$.

${ }^{b} p$ value $=0.020$ vs. non $A A T D$.

Table 4. General characteristics and lung function tests among the different genotypes. 


\begin{tabular}{|c|c|c|c|c|c|c|c|}
\hline Variables & $\mathrm{PI}$ MS & $\mathrm{PI} * \mathrm{MZ}$ & $\mathrm{PI} * \mathrm{MM}$ & $\mathrm{PI}{ }^{\star} \mathrm{MS}$ & $\mathrm{PI}$ MM & $\mathrm{PI} * \mathrm{MZ}$ & $\mathrm{PI} * \mathrm{MM}$ \\
\hline $\begin{array}{l}\text { Subjects, } \\
\mathrm{nr}\end{array}$ & 11 & 9 & 35 & 11 & 35 & 9 & 35 \\
\hline $\begin{array}{l}\mathrm{BMI}, \\
\mathrm{kg} / \mathrm{m}^{2}\end{array}$ & $28.0 \pm 2.6$ & $29.3 \pm 7.1$ & $25.5 \pm 4.2$ & $28.0 \pm 2.6$ & $25.5 \pm 4.2$ & $29.3 \pm 7.1$ & $25.5 \pm 4.2$ \\
\hline $\begin{array}{l}\text { AAT level, } \\
\mathrm{mg} / \mathrm{dL}\end{array}$ & $100.0[97.8 ; 110.0]$ & $90.7[77.2 ; 99.9]^{p}$ & $111.0[105.0 ; 115.0]$ & $100.0[97.8 ; 110.0]$ & $111.0[105.0 ; 115.0]$ & $90.7[77.2 ; 99.9]^{c}$ & $111.0[105.0 ; 115.0$ \\
\hline FVC, L & $3.12 \pm 1.00$ & $3.04 \pm 1.05$ & $3.80 \pm 1.14$ & $3.12 \pm 1.00$ & $3.80 \pm 1.14$ & $3.03 \pm 1.05$ & $3.80 \pm 1.14$ \\
\hline $\begin{array}{l}\text { FVC, \% } \\
\text { predicted }\end{array}$ & $102.7 \pm 16.6$ & $99.3 \pm 14.2$ & $112.3 \pm 15.9$ & $102.7 \pm 16.6$ & $109.0[103.6 ; 127.0]$ & $97.2[91.5 ; 114.0]^{d}$ & $109.0[103.6 ; 127.0$ \\
\hline TLC, L & $5.39 \pm 0.92$ & $5.30 \pm 0.89$ & $6.08 \pm 1.16$ & $5.39 \pm 0.92$ & $6.08 \pm 1.16$ & $5.30 \pm 0.86$ & $5.91[5.12 ; 6.95]$ \\
\hline $\begin{array}{l}\mathrm{RV} / \mathrm{TLC}, \\
\%\end{array}$ & $43.2 \pm 9.6$ & $42.8 \pm 11.5$ & $36.3 \pm 9.5$ & $43.2 \pm 9.6^{b}$ & $36.3 \pm 9.5$ & $42.9 \pm 11.5$ & $36.3 \pm 9.5$ \\
\hline $\begin{array}{l}\mathrm{FEV}_{3}, \% \\
\text { predicted }\end{array}$ & $87.9 \pm 21.3$ & $82.9 \pm 11.0$ & $95.9 \pm 12.1$ & $87.9 \pm 21.3$ & $95.9 \pm 12.1$ & $82.9 \pm 11.0^{e}$ & $95.9 \pm 12.1$ \\
\hline $\mathrm{FEV}_{3}, \mathrm{~L}$ & $2.77 \pm 1.15$ & $2.70 \pm 1.01$ & $3.38 \pm 1.09$ & $2.77 \pm 1.15$ & $3.38 \pm 1.09$ & $2.70 \pm 1.00$ & $3.38 \pm 1.09$ \\
\hline $\mathrm{FEV}_{6}, \mathrm{~L}$ & $2.73 \pm 0.87$ & $2.78 \pm 1.00$ & $3.55 \pm 1.16$ & $2.73 \pm 0.87$ & $3.55 \pm 1.16$ & $2.77 \pm 1.00$ & $3.55 \pm 1.16$ \\
\hline $\begin{array}{l}\mathrm{R} 20 \text {, } \\
\mathrm{kPa} /(\mathrm{L} / \mathrm{s})\end{array}$ & $0.40 \pm 0.08$ & $0.38 \pm 0.06$ & $0.34 \pm 0.12$ & $0.39 \pm 0.08$ & $0.34 \pm 0.12$ & $0.38 \pm 0.63$ & $0.32[0.30 ; 0.40]$ \\
\hline $\begin{array}{l}\text { R5-R20, } \\
\mathrm{kPa} /(\mathrm{L} / \mathrm{s})\end{array}$ & $0.08 \pm 0.09$ & $0.08 \pm 0.09$ & $0.07 \pm 0.07$ & $0.08 \pm 0.09$ & $0.07 \pm 0.07$ & $0.08 \pm 0.09$ & $0.07 \pm 0.07$ \\
\hline
\end{tabular}

Data are shown as means $\pm S D$ or medians [1st quartile; 3rd quartile].

Boldface variables are statistically significant.

Abbreviations: $n r$, number.

${ }^{a} p$ value $=0.016 \mathrm{vs} . P /{ }^{*} M S$ patients and $P / * M Z$ patients

${ }^{b} p$ value $=0.043 v s . P / * M M$ and $P / * M S$ patients.

${ }^{c} p$ value $=0.000,{ }^{d} p$ value $=0.040,{ }^{e} p$ value $=0.007 v s . P I * M M$ and $P{ }^{\star} M Z$ patients.

${ }^{f} p$ value $=0.019,{ }^{g} p$ value $=0.000,{ }^{h} p$ value $=0.023,{ }^{i} p$ value $=0.013,{ }^{j} p$ value $=0.040,{ }^{k} p$ value $=0.016,{ }^{\prime} p$ value $=0.018,{ }^{m} p$ value $=0.049,{ }^{n} p$ value $=0.020,{ }^{o} p$ value $=0.029$, vs. not AATD and PI*MS, MZ patients.

Figures 


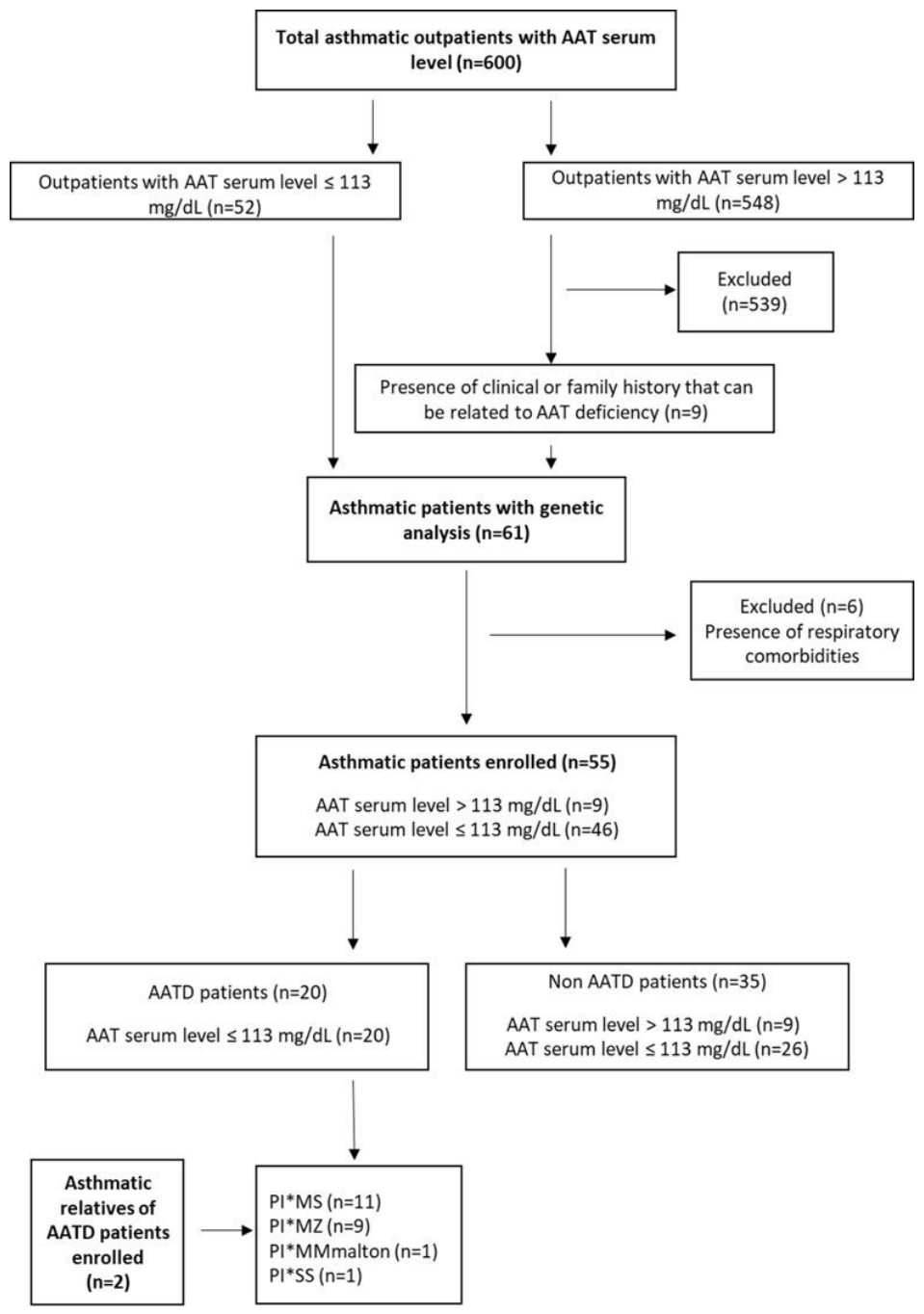

\section{Figure 1}

Consort diagram of the study protocol

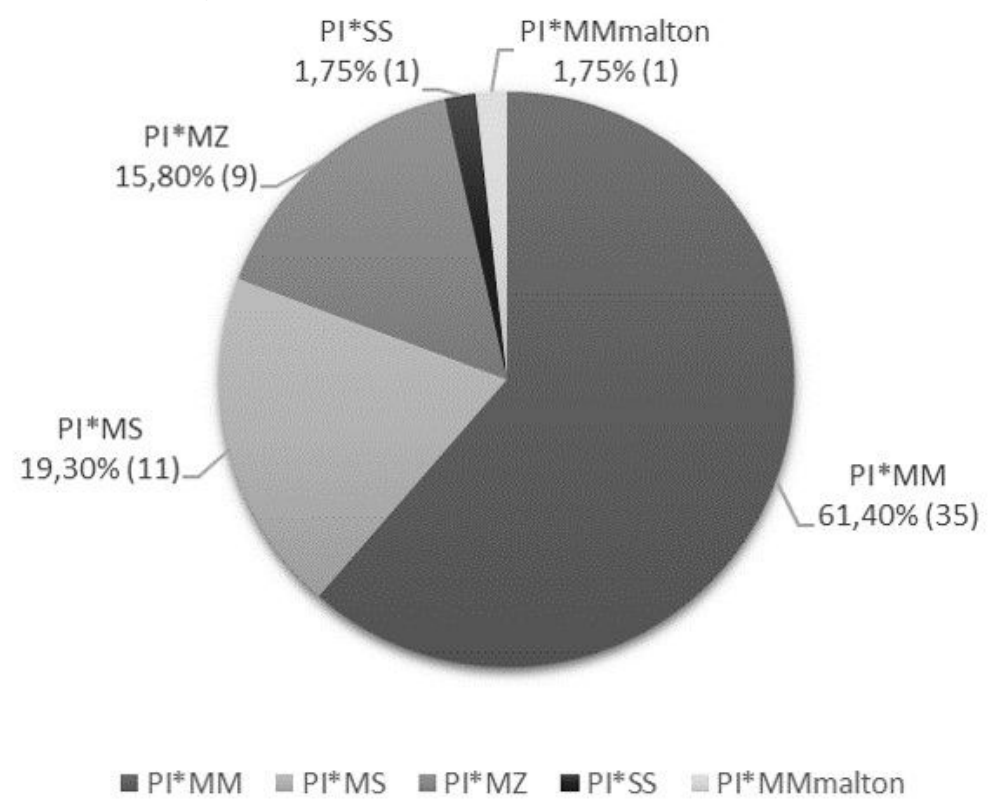

Figure 2

AAT genotype distribution among asthmatic patients 


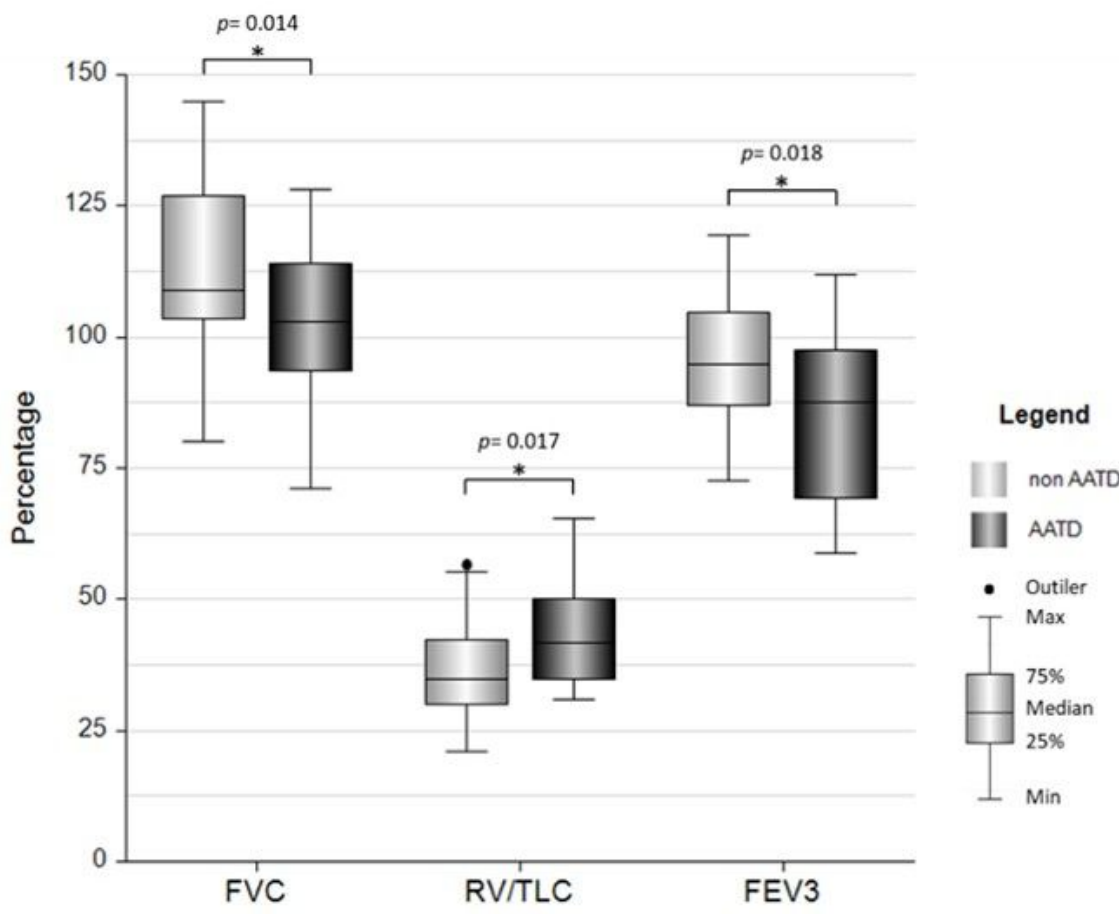

Figure 3

FVC, RV/TLC ratio and FEV3 vs. non AATD. The outer edges of the box represent the interquartile range (1st and 3rd quartile), the solid line within the box is the median, and whiskers indicate the minimum and maximum values. Black dot represents an outlier of the data. The $*$ indicates that the difference between the two groups is statistically significant.

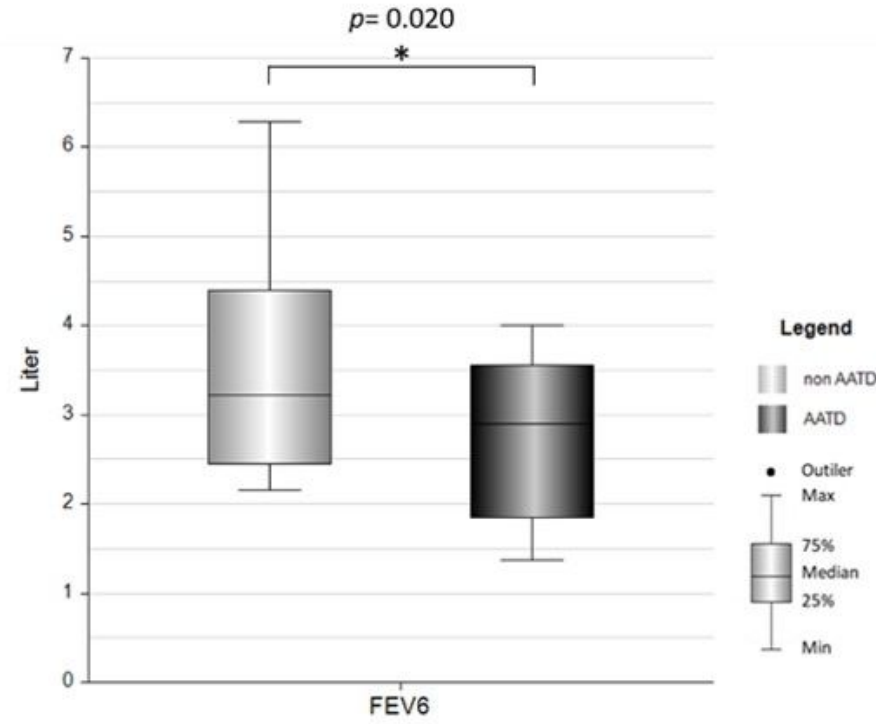

Figure 4

FEV6 vs. non AATD. The outer edges of the box represent the interquartile range (1st and 3rd quartile), the solid line within the box is the median, and whiskers indicate the minimum and maximum values. The $*$ indicates that the difference between the two groups is statistically significant. 


\section{Test variable: presence of AAT mutation}

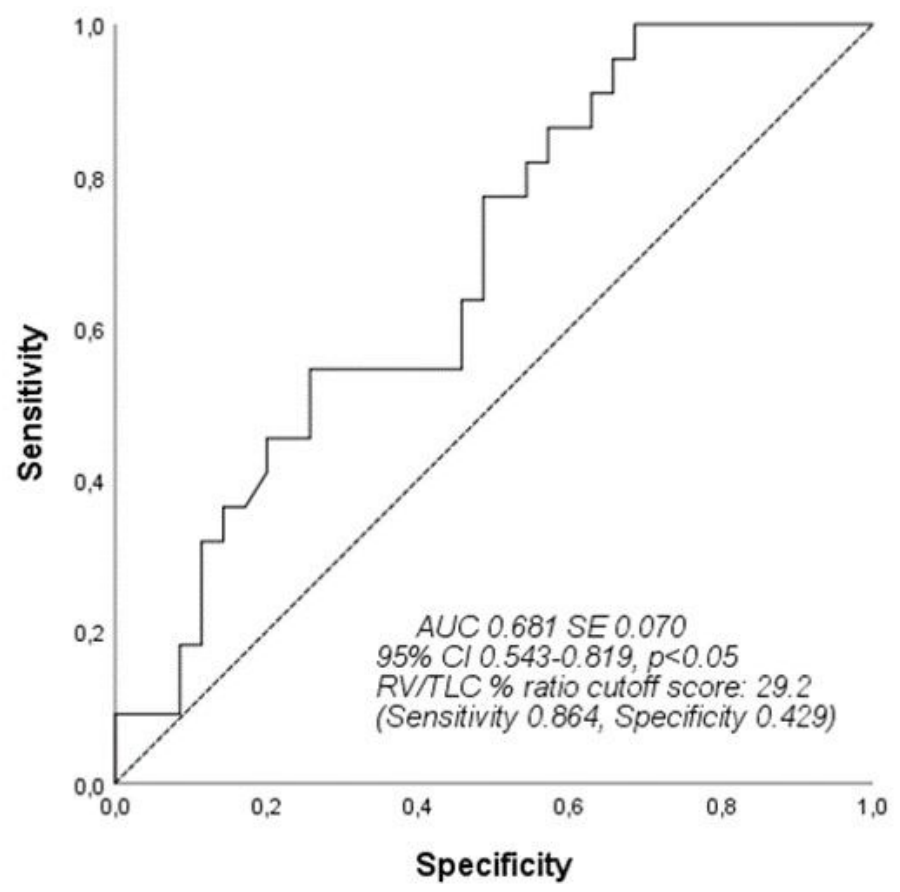

Figure 5

Receiver operating characteristic curve for RV/TLC ratio (\%) calculated with presence of AAT mutation as test variable in asthmatic patients. The dashed line indicates the reference line. AUC, area under the curve; SE, standard error. 